\title{
Relationship Between Insulin-Like Growth Factor-I and Brain Natriuretic Peptide in Patients With Acromegaly After Surgery
}

\author{
Masahiro Ito, MD; Makoto Kodama, MD; Itaru Tsumanuma, MD*; \\ Mahmoud M. Ramadan, MD; Satoshi Hirayama, MD; Takashi Kamimura, MD; \\ Takeshi Kashimura, MD; Koichi Fuse, MD; Satoru Hirono, MD; \\ Yuji Okura, MD; Yoshifusa Aizawa, MD
}

\begin{abstract}
Background Increased cardiac insulin-like growth factor (IGF)-I production is associated with physiological cardiac hypertrophy in athletes, and IGF-I has been recognized as a cardioprotective agent in experimental animal studies. On the other hand, acromegaly which is characterized by an excess of IGF-I has been linked to impaired cardiac function.

Methods and Results Both the relationship between the serum levels of IGF-I and brain natriuretic peptide (BNP), which is released from the cardiac ventricles in response to ventricular stress, and that between IGF-I and the concentrations of the plasma amino-terminal propeptide of procollagen type III (P-III-P), which is associated with myocardial fibrosis, were evaluated in 19 patients after surgical treatment for acromegaly. Echocardiography revealed that left ventricular systolic function and dimensions were within normal range in all patients. Significant inverse correlations were found between IGF-I and the BNP $(r=-0.5, p=0.02)$ and P-III-P levels $(\mathrm{r}=-0.62, \mathrm{p}=0.005)$.

Conclusion We observed an inverse significant relationship between IGF-I and both the BNP and P-III-P value in surgically treated acromegaly patients. These observations suggest that appropriate levels of IGF-I have beneficial cardioprotective effects after surgery in patients with acromegaly. (Circ J 2007; 71: 1955-1957)
\end{abstract}

Key Words: Acromegaly; Brain natriuretic peptide; Insulin-like growth factor-I

I nsulin-like growth factor (IGF)-I is an important factor not only in the regulation of postnatal growth of the heart but also in the pathogenesis of left ventricular $(\mathrm{LV})$ remodeling! It has been reported to have beneficial effects on the heart by improving cardiac contractility, reducing cell death and may also promote myocardial "physiological" hypertrophy 1,2 On the other hand, acromegaly is characterized by an excess of both growth hormone (GH) and its tissue effector, IGF-I 3 , and despite the beneficial effects of IGF-I, some patients with acromegaly develop cardiac dysfunction, a condition referred to as "acromegalic cardiomyopathy". The underlying mechanisms of this paradoxical phenomenon are still obscure. These observations have lead to the hypothesis that appropriate GH/IGF levels are mandatory for their beneficial effects.

There have been no previous reports regarding the relationship between IGF-I and brain natriuretic peptide (BNP) in patients with acromegaly, so the purpose of this study was to investigate the possible relationship between the serum levels of IGF-I and BNP, which is released from the cardiac ventricles in response to ventricular stress, 5 in patients treated surgically for acromegaly. Furthermore, we assessed the relationship between IGF-I and the concentrations of the

(Received November 24, 2006; revised manuscript received August 17, 2007; accepted August 28, 2007)

Division of Cardiology, *Department of Neurosurgery, Brain Institute, Niigata University School of Medicine, Niigata, Japan

Mailing address: Masahiro Ito, MD, Division of Cardiology, Niigata University School of Medicine, 1-754 Asahi-machi, Niigata 951-8510,

Japan. E-mail. masaboston2001@yahoo.co.jp plasma amino-terminal propeptide of procollagen type III (P-III-P), which is associated with myocardial fibrosis6

\section{Methods}

After excluding those with post-surgical panhypopituitarism, 30 patients who had been surgically treated for acromegaly were eligible to be included in the present study. Acromegaly was diagnosed on the basis of consensus criteria? We further excluded 11 patients for the following reasons: hypertension managed with therapeutic drugs, because of the influence on the value of BNP, or treatment by somatostatin analog in addition to operation. Finally, 19 patients were included in this analysis. Only 2 patients were treated with bromocriptine. All subjects gave informed consent. The duration of acromegaly was assumed to be the interval between the clinical onset, as determined from the patient's interview, and the time of treatment. The patients were free of liver, renal, and skeletal disease known to influence the concentrations of P-III-P.

Blood samples were obtained from each patient and the serum BNP level was measured by chemiluminescent enzyme immunoassay, and those of IGF and P-III-P were measured by immunoradiometric assay. Intra- and interassay variabilities of BNP measurements were $5 \%$ for each, and for IGF-I and P-III-P were $2 \%$ and $3 \%$ for each, respectively. The reference values were $<18.4 \mathrm{pg} / \mathrm{ml}$ for BNP and $0.3-0.8 \mathrm{U} / \mathrm{ml}$ for P-III-P. Echocardiographic examinations were performed and LV mass (LVM) was calculated by the Devereux and Reicheck formula: LVM=1.04\{(IVSd+ 
Table 1 Baseline Characteristics of the Study Population

\begin{tabular}{lc}
\hline \hline M/F & $8 / 11$ \\
Age (years) & $62.8 \pm 2.5$ \\
Age at onset (years) & $40.5 \pm 3.0$ \\
Duration before surgery (years) & $8.7 \pm 1.9$ \\
Duration after surgery (years) & $13.6 \pm 1.9$ \\
GH level $(\mathrm{ng} / \mathrm{ml})$ & $1.58 \pm 2.0$ \\
IGF-I level $(\mathrm{ng} / \mathrm{ml})$ & $198.7 \pm 21.7$ \\
$P$-III-P level $(\mathrm{U} / \mathrm{ml})$ & $0.73 \pm 0.03$ \\
BNP level $(\mathrm{pg} / \mathrm{ml})$ & $32.4 \pm 6.6$ \\
Systolic blood pressure $(\mathrm{mmHg})$ & $125.0 \pm 11.6$ \\
Diastolic blood pressure $(\mathrm{mmHg})$ & $75.5 \pm 7.6$ \\
LVMI $\left(\mathrm{g} / \mathrm{m}^{2}\right)$ & \\
Male & $121.2 \pm 12.8$ \\
Female & $104.4 \pm 6.1$ \\
EF $(\%)$ & $66.2 \pm 5.7$ \\
\end{tabular}

GH, growth hormone; IGF-I, insulin-like growth-factor I; P-III-P, plasma amino-terminal propeptide of procollagen type III; BNP, brain natriuretic peptide; LVMI, left ventricular mass index; EF, ejection fraction.

PWd + LVDD $)^{3}-$ LVDD $\left.^{3}\right\}-13.6$ g. LV hypertrophy (LVH) was diagnosed when LVM, indexed for the body surface area (LVMI), was $\geq 135 \mathrm{~g} / \mathrm{m}^{2}$ in males and $\geq 110 \mathrm{~g} / \mathrm{m}^{2}$ in females. All data are expressed as mean \pm SEM. Normality of distribution of the values of different variables was assessed by the 1-sample Kolmogorov-Smirnov test. All variables were normally distributed. Correlations between the values of continuous variables were performed using the Pearson correlation coefficient. Statistical significance was assumed at a 2-tailed level of $\mathrm{p}<0.05$.

\section{Results}

Table 1 shows the baseline characteristics of our study population. The mean age at the onset of the disease was $40 \pm 3.0$ years. The mean estimated disease duration before and after surgery was $8.7 \pm 1.9$ and $13.6 \pm 1.9$ years, respectively. Echocardiography revealed that LV systolic function and dimensions were within the normal range in all patients. Five patients (26\%) had LVH defined by LVMI. No patient showed symptoms of heart failure or a past history of congestive heart failure.

The mean serum concentration of BNP, IGF-I and P-III-P was $32.4 \pm 6.6 \mathrm{pg} / \mathrm{ml}, 198.7 \pm 21.7 \mathrm{ng} / \mathrm{ml}$, and $0.73 \pm 0.03 \mathrm{U} / \mathrm{ml}$, respectively. As shown in Fig 1, there was an inverse significant correlation of moderate strength between the levels of IGF-I and BNP ( $r=-0.5, p=0.02)$. We also found an inverse, significant, strong correlation between the IGF-I and $\mathrm{P}$-III-P levels $(\mathrm{r}=-0.62, \mathrm{p}=0.005)$. The correlation of age to BNP, IGF-I, and P-III-P was $r=0.3(p=0.22), r=-0.3(p=$
$0.15)$, and $\mathrm{r}=0.4(\mathrm{p}=0.08)$, respectively. After adjustment for age, the inverse correlation between IGF-I and P-III-P remained significant and of moderate power $(r=-0.47$, $\mathrm{p}=0.04$ ), whereas the correlation between IGF-I and BNP became of borderline significance $(r=-0.42, p=0.08)$. However, in terms of the moderate power of the correlation coefficient (ie, $18 \%$ of the total variance of BNP values can be explained by changes in IGF-I level), this result remains important, irrespective of the borderline statistical significance, because of the high possibility of getting significant results on studying a larger sample size. Echocardiographic parameters, such as left atrial diameter, LV dimensions, LV thickness, and ejection fraction had weak non-significant correlations with IGF-I $(r=0.1-0.2, p=0.15-0.3)$. Similarly, both BNP and the ejection fraction had weak non-significant correlations with the postoperative duration of disease $(\mathrm{r}=0.1, \mathrm{p}=0.15$ and $\mathrm{r}=0.2, \mathrm{p}=0.2$, respectively $)$.

\section{Discussion}

The principal finding of this study is that BNP and IGF-I had an inverse relationship in patients treated surgically with acromegaly without impaired systolic function. Furthermore, our results revealed that the IGF-I level negatively correlated with the P-III-P value.

Acromegaly is characterized by an excess of both $\mathrm{GH}$ and IGF-I? The serum level of IGF-I has little circadian rhythm, reflecting the biological activity of GH secretion, and the specific receptors for IGF-I in the heart promote cardiac remodeling. Circulating IGF-I is mainly synthesized in the liver, but recently it was suggested that IGF-I is produced in other tissues, including the heart?

The role of the GH-IGF-I system in heart failure is equivocal. Clinical studies have shown that the serum IGF-I level is inversely related to congestive heart failure and ischemic heart disease ${ }^{8,9}$ Both cardiac and circulating IGF-I are associated with physiological cardiac hypertrophy in athletes ${ }^{10,11}$ Transgenic mice overexpressing the IGF-I receptor in the heart display physiological cardiac hypertrophy, and in an experimental model of heart failure the GH-IGF-I axis has a beneficial effect!,12,13 At the transcriptional level, it has been reported that IGF-I-mediated cardiac hypertrophy is distinct from that induced by pathological stress, such as pressure overload? Those results indicate that the IGF-I is a potential therapeutic option for the treatment of heart failure; however, clinical trials have questioned this. Recently, Shiojima et al reported elegant findings regarding the role of Akt, which is a well-known main downstream target of IGF-I; cardiac-specific inducible Akt transgenic mice developed adaptive or physiological hypertrophy following
A

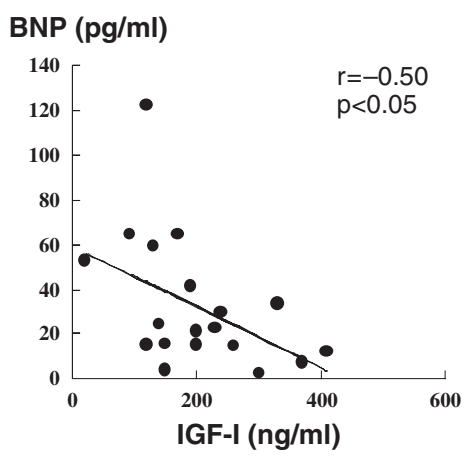

$B$

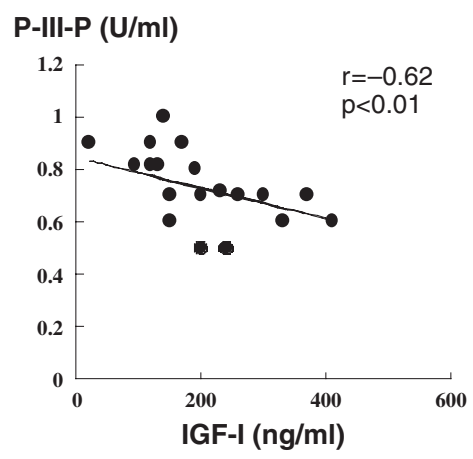

Fig 1. Pearson correlation coefficients between insulinlike growth factor (IGF)-I and brain natriuretic peptide (BNP) (A), and between IGF-I and plasma amino-terminal propeptide of procollagen type III (P-III-P) (B). 
short-term transgene induction, but exhibited pathological hypertrophy and cardiomyopathy with longer periods of transgene induction ${ }^{14}$ which suggests that an appropriate IGF-I level is mandatory for its beneficial effects.

Abe et al reported that IGF-I production in the heart, but not the plasma total IGF-I level, was increased in patients with LV dysfunction and advanced heart failure, and positively correlated with the plasma BNP level 15 Their results indicate that the local cardiac IGF-I system is upregulated with the progression of LV dysfunction. In contrast, although cardiac hypertrophy defined by LVMI existed in $26 \%$ of the present patients, neither ventricular dilation nor symptoms of heart failure were detected. All patients had been treated surgically and the IGF-I level was not extremely high. Thus, taken together with the previous reports, our results imply that an adequate level and duration of rise of IGF-I may have beneficial effects on the myocardium in humans without impaired systolic function, and that it exhibits an inverse relationship with the level of BNP.

The inverse correlation of IGF-I and P-III-P may be explained by the inverse relationship between IGF-I and BNP. BNP is released from the cardiac ventricles in response to ventricular stress, whereas myocardial fibrosis would progress with increased wall stress ${ }^{16}$ The circulating level of P-III-P reflects tissue fibrosis. Thus, these findings suggest that an adequate level of IGF-I would decrease LV wall stress, resulting in suppression of myocardial fibrosis.

Acromegalic cardiomyopathy has different characteristics in relation to the clinical stage of acromegaly. In the early stage, cardiac contractility increases and there is a higher cardiac output. In the middle stage, concentric myocardial hypertrophy with interstitial fibrosis predominates. Finally, ventricular dilatation with impaired cardiac performance develops. The duration and activity of the disease determine the cardiac involvement in acromegaly ${ }^{17}$ Interestingly, the acromegalic heart shares very few features with other models of heart failure before the transition from adaptive/ physiological cardiac growth to maladaptive translates into heart failure? In the experimental study of Delaughter et al ${ }^{18}$ it was shown that local IGF-I expression induces physiologic, then pathologic, cardiac hypertrophy in transgenic mice. Those findings may denote that in the early phase of the natural progression of acromegaly, salutary cardiac remodeling and/or physiological hypertrophy could occur and therefore the present patients may have been in that phase.

GH deficiency (GHD) is known to induce abnormalities of cardiac structure and function, and replacement therapy may have beneficial effects. ${ }^{19}$ Wallaschofski et al reported that GH replacement therapy decreased BNP levels, associated with an improvement of heart failure status in patients with GHD and increased baseline BNP levels ${ }^{20}$ As we did not determine GHD status in the study patients, we cannot exclude that some patients had GHD, which might affect our results.

\section{Study Limitations}

These should be considered in the interpretation of our results, such as the small sample size. In addition, the values of BNP and P-III-P were assayed only at a single time point. Therefore, our results should be confirmed in a larger prospective trial. In addition, further study is needed to determine the optimal IGF-I level for the beneficial effect on the myocardium.

In conclusion, we observed an inverse significant relationship between IGF-I and both the BNP and P-III-P value in surgically treated acromegaly patients. There is increasing evidence that IGF-I could be cardioprotective and the present findings indicate potentially important implications for the role of IGF-I in the heart.

\section{References}

1. Saetrum Opgaard O, Wang PH. IGF-I is a matter of heart. Growth Horm IGF Res 2005; 15: 89-94.

2. Ceci M, Ross J Jr, Condorelli G. Molecular determinants of the physiological adaptation to stress in the cardiomyocyte. J Mol Cell Cardiol 2004; 37: 905-912.

3. Giustina A, Barkan A, Casanueva FF, Cavagnini F, Frohman L, Ho $\mathrm{K}$, et al. Criteria for cure of acromegaly. J Clin Endocrinol Metab 2000; 85: 526-529.

4. Sacca L, Napoli R, Cittadini A. Growth hormone, acromegaly, and heart failure. Clin Endocrinol 2003; 59: 660-671.

5. Yasue H, Yoshimura M, Sumida H, Kikuta K, Kugiyama K, Jougasaki $\mathrm{M}$, et al. Localization and mechanism of secretion of B-type natriuretic peptide in comparison with those of A-type natriuretic peptide in normal subjects and patients with heart failure. Circulation 1994; 90: $195-203$.

6. Cicoira M, Rossi A, Bonapace S, Zanolla L, Golia G, Franceschini L, et al. Independent and additional prognostic value of aminoterminal propeptide of type III procollagen circulating levels in patients with chronic heart failure. J Card Fail 2004; 10: 403-411.

7. Neri Serneri GG, Modesti PA, Boddi M, Cecioni I, Paniccia R, Coppo M, et al. Cardiac growth factors in human hypertrophy: Relations with myocardial contractility and wall stress. Circ Res 1999; 85: $57-67$.

8. Vasan RS, Sullivan LM, D'Agostino RB, Roubenoff R, Harris T, Sawyer DB, et al. Serum insulin-like growth factor I and risk for heart failure in elderly individuals without a previous myocardial infarction: The Framingham Heart Study. Ann Intern Med 2003; 139: $642-648$.

9. Juul A, Scheike T, Davidsen M, Gyllenborg J, Jorgensen T. Low serum insulin-like growth factor I is associated with increased risk of ischemic heart disease. Circulation 2002; 106: 939-944.

10. Neri Serneri GG, Boddi M, Modesti PA, Cecioni I, Coppo M, Padeletti L, et al. Increased cardiac sympathetic activity and insulinlike growth factor-I formation are associated with physiological hypertrophy in athletes. Circ Res 2001; 89: 977-982.

11. Koziris LP, Hickson RC, Chatterton RT Jr, Groseth RT, Christie JM, Goldflies DG, et al. Serum levels of total and free IGF-I and IGFBP3 are increased and maintained in long-term training. J Appl Physiol 1999; 86: $1436-1442$.

12. McMullen JR, Shioi T, Huang WY, Zhang L, Tarnavski O, Bisping $\mathrm{E}$, et al. The insulin-like growth factor 1 receptor induces physiological heart growth via the phosphoinositide 3-kinase (p110a) pathway. J Biol Chem 2004; 279: 4782-4793.

13. Bollano E, Bergh CH, Kjellstrom C, Omerovic E, Kujacic V, Caidahl $\mathrm{K}$, et al. Growth hormone alone or combined with metoprolol preserves cardiac function after myocardial infarction in rats. Eur $J$ Heart Fail 2001; 3: 651-660.

14. Shiojima I, Sato K, Izumiya Y, Schiekofer S, Ito M, Liao R, et al. Disruption of coordinated cardiac hypertrophy and angiogenesis contributes to the transition to heart failure. J Clin Invest 2005; 115: $2108-2118$.

15. Abe N, Matsunaga T, Kameda K, Tomita H, Fujiwara T, Ishizaka H, et al. Increased level of pericardial insulin-like growth factor-1 in patients with left ventricular dysfunction and advanced heart failure. J Am Coll Cardiol 2006; 48: 1387-1395.

16. Weber KT. Fibrosis and hypertensive heart disease. Curr Opin Cardiol 2000; 15: 264-272.

17. Colao A, Cuocolo A, Marzullo P, Nicolai E, Ferone D, Della Morte $\mathrm{AM}$, et al. Impact of patient's age and disease duration on cardiac performance in acromegaly: A radionuclide angiography study. J Clin Endocrinol Metab 1999; 84: 1518-1523.

18. Delaughter MC, Taffet GE, Fiorotto ML, Entman ML, Schwartz RJ. Local insulin-like growth factor I expression induces physiologic, then pathologic, cardiac hypertrophy in transgenic mice. FASEB $J$ 1999; 13: 1923-1929.

19. Meyers DE, Cuneo RC. Controversies regarding the effects of growth hormone on the heart. Mayo Clin Proc 2003; 78: 1521-1526.

20. Wallaschofski H, Saller B, Spilcke-Liss E, Lerch MM, Lohmann T, Eigenthaler M. Effects of growth hormone treatment on B-type natriuretic peptide as a marker of heart failure in adults with growth hormone deficiency. Horm Metab Res 2006; 38: 656-661. 